DOI: $\underline{10.17805 / g g z .2019 .4 .6}$

\title{
Эмоциональный интеллект и коммуникативные способности современных студентов
}

\author{
А. И. Полянский, \\ Л. И. Быковская
}

Московский гуманитарный университет

В работе дается теоретический обзор ключевых понятий («эмочиональный интеллект», «коммуникативные способности личности» и «организаторские способности личности»), приведены основные подходы и направления изучения перечисленных понятий. Также статья содержит краткое описание результатов эмпирического исследования рассматриваемых психологических явлений у студентов российских вузов. Публикуются программа эмпирического исследования, первичные данные психодиагностики респондентов и результаты статистической обработки данных. Представлены выводы по полученным результатам, краткая характеристика их практической значимости и дальнейшие перспективы исследования по данной теме.

Ключевые слова: эмочиональный интеллект; способность; икала эмоционального интеллекта; эмоция

\section{Emotional Intelligence and Communicative Abilities of Modern Students}

\author{
A. I. Polyansky, \\ L. I. Bykovskaya \\ Moscow University for the Humanities
}

The article gives a theoretical review of the key concepts "emotional intelligence", "communicative abilities of the person" and "organizational abilities of the person". It covers the main approaches and directions of research relating to these concepts. Also, the article contains a short description of the results of an empirical research on the psychological phenomena in students of Russian HEIs. The authors introduce the program of the empirical research and set out the primary data on the psychological diagnostics of respondents and results of statistical data processing. The article presents conclusions regarding the obtained results, a short description of their practical significance and future prospects of research on this topic. 
Keywords: emotional intelligence; ability; emotional intelligence scale; emotion

\section{ВВЕДЕНИЕ}

Настоящая статья посвящена значению эмоций в контексте общения и взаимодействия личности с окружающим миром, в частности, контактирования с другими людьми. Многими исследованиями установлено, что не только когнитивная, но также и эмоциональная сфера личности способствует успешному и эффективному взаимодействию, адаптации личности к внешним условиям в целом. Е. П. Ильин отмечает, что эмоции представляют собой «рефлекторную психовегетативную реакцию; связанную с проявлением субъективного пристрастного отношения (в виде переживания) к ситуации, ее исходу (событию) и способствующую организации целесообразного поведения в этой ситуации» (Ильин, 2001: 50). Из этого утверждения следует, что благодаря эмоциям человек может корректировать свое поведение для достижения положительного результата в какой-либо ситуации. Следовательно, эмоции могут оказывать позитивное влияние на качество общения человека, позволяя ему выстраивать взаимодействие и коммуникацию с другими людьми наиболее подходящим в конкретных обстоятельствах образом.

Интерес для исследователей представляет также вопрос возникновения и развития эмоционального интеллекта. Вследствие приобретения эмоциями более высокого статуса в науке начали появляться такие понятия, как «социальная и эмоциональная компетентность» Р. Бака (Buck, 1991), «эмоциональный интеллект» Г. Гарднера (Gardner, 1993), Дж. Майера, Д. Карузо, П. Сэловея (Mayer, Caruso, Salovey, 1999), термин “EQ” (emotional quotient) — коэффициент эмоционального интеллекта (Bar-On, 1997, 2000). Вместе с тем на данный момент отсутствует единая теория эмоционального интеллекта, научные знания о данном феномене остаются неполными. На сегодняшний день наиболее изучена структура эмоционального интеллекта, однако его влияние на другие сферы личности пока остается малоисследованным. В этом также заключается актуальность нашей работы.

Понятие «эмоциональный интеллект» появилось в современной психологии в начале 1990-х гг., его ввели П. Сэловей и Дж. Майер (Salovey, Mayer, 1990). Позднее эти же авторы и их коллеги разработали теорию, по которой эмоциональный интеллект наряду с социальным, практическим и личностным интеллектом является одним из видов горячего интеллекта (Большой психологический словарь, 2009: 763). Сейчас в мире научной психологии известно несколько теорий, описывающих феномен эмоционального интеллекта. Помимо теории эмоционально-интеллектуальных способностей 
Дж. Майера, Д. Карузо, П. Сэловея (Mayer, Caruso, Salovey, 1999) можно отметить теорию эмоциональной компетентности Д. Гоулмена (Goleman, 1995) и некогнитивную теорию эмоционального интеллекта Р. Бар-Она (Bar-On, 2000).

Один из подходов, получивший обозначение эмоционального интеллекта, был разработан в конце 80-х годов прошлого столетия психологами П. Сэловеем и Дж. Майером (Salovey, Mayer, 1990). Их интеллектуальный подход к эмоциям включает в себя четыре разных умения, которые находятся в иерархическом соотношении друг с другом, а именно: 1) идентификация эмоций; 2) использование эмоций; 3) понимание эмоций; 4) умение управлять эмоциями (Карузо, Сэловей, 2018: 13-15).

Первыми исследователями, заговорившими на тему эмоционального интеллекта в бизнес-литературе, стали Д. Гоулман (Goleman, 1995) и М. Кетс де Врис (Kets de Vries, 2001). Согласно концепции Гоулмана, эмоциональный интеллект предполагает способность личности распознавать свои и чужие эмоции, управлять ими (Гоулман, 2018: 19-20). Ученый считает, что именно степень компетентности человека в эмоциональной жизни и ее функциях, составляющих набор определенных компетенций, и имеет «решающее значение для понимания, почему один преуспевает в жизни, а другой - интеллектуально равный - оказывается в тупике» (там же: 77). Таким образом, согласно данной точке зрения, эмоциональный интеллект необходим для достижения социального успеха в жизни.

Отметим также кратко компоненты, которые, по мнению Д. Гоулмана, Р. Бояциса и Э. Макки, входят в понятие «эмоциональный интеллект», (Goleman, Boyatzis, McKee, 2002). В список составляющих эмоционального интеллекта исследователи включают самосознание, социальную чуткость и управление отношениями, каждая из которых, в свою очередь, подразделяется на несколько единиц (Гоулман, Бояцис, Макки, 2018: 266-269).

Исследования эмоционального интеллекта современными отечественными учеными в основном носят практико-ориентированный, прикладной характер, о чем свидетельствуют неоднократные попытки найти оптимальный способ диагностики выраженности эмоционального интеллекта и его измерения. Среди российских исследователей пионером изучения данного феномена считается Д. В. Люсин, создавший собственную оригинальную модель эмоционального интеллекта и свою методику диагностики степени выраженности эмоционального интеллекта («Опросник ЭмИн»). Ученый рассматривает эмоциональный интеллект в качестве способности к пониманию эмоций (своих и чужих) и к управлению этими эмоциями, связывая указанные способности с такими характеристиками личности, как общая направ- 
ленность на сферу эмоций, наличие интереса как к собственному внутреннему миру, так и к внутренним мирам других людей (Люсин, 2004: 33-34). Поскольку возможность личности понимать эмоции и управлять ими может быть направлена как на себя, так и на окружающих, Люсин выделяет внутриличностный (ВЭИ) и межличностный эмоциональный интеллект (МЭИ) (Люсин, 2006: 6-7).

Взаимосвязи этого феномена с различными психологическими явлениями и пути их изучения с психометрической точки зрения также представлены в работах И. Н. Андреевой, Д. В. Ушакова, С. П. Деревянко, О. А. Гулевич, В. А. Барабанщикова, В. В. Овсянниковой, Е. А. Сергиенко, Т. А. Сысоевой и др.

Как отмечает в своей работе Э. Д. Бабудоржиева, вопрос о коммуникативных и организаторских способностях на сегодняшний день является одной из наиболее актуальных тем в современной психологической теории общих и специальных способностей. Стремительное развитие информационных технологий, требующее все бо́льшей эффективности навыков коммуникации, приводит к росту необходимости в прикладных разработках в данной области (Бабудоржиева, 2012: 41).

В исследованиях западных ученых коммуникативные способности рассматривались в контексте специальных способностей. В основе подобных исследований лежит психометрический подход, позволяющий сопоставлять способности, измеренные различными тестами, путем факторного анализа. Представителями данного направления являются Ч. Спирмен (Spearman, 1927), Л. Терстоун (Thurstone, 1947), Д. Векслер (Wechsler, 1955), Дж. Гилфорд (Guilford, 1967), Р. Б. Кеттелл (Cattell, 1971) и мн. др. Анализируя данный вопрос, Ю. В. Аникеева пишет: «Все западные теории преимущественно исходят из попытки определить компонентный состав способностей, выявить такую иерархическую модель, которая была бы вполне достаточной для полного описания способностей человека, как общих, так и специальных» (Аникеева, 2012: 14).

Коммуникативные способности личности в разное время изучали такие отечественные ученые, как С. Л. Рубинштейн, В.Н.Мясищев, К. К. Платонов, Г. С. Васильев, А. Г. Ковалев, А. А. Кидрон, Н. В. Кузьмина, Л. М. Митина, Э. А. Голубева, М. К. Кабардов, В. В. Бурлаков, Н. И. Карасева, Е. А. Кукуев, Т. П. Абакирова, Н. А. Воробьева и др. При этом исследователи используют разнообразные термины для определения явлений, связанных с коммуникацией и общением, например: коммуникативные способности, коммуникативный потенциал, коммуникативная компетентность, общительность, социально-психологическая компетентность и пр. (Бабудоржиева, 
2012: 42). Но, несмотря на попытки соотнесения между собой данных терминов, выработать строгую научную иерархию между ними специалистам пока не удалось.

Различные аспекты организаторских способностей представлены в работах таких психологов, как Р. М. Стогдилл, Э. Гизелли, Б. Г. Ананьев, В. Н. Мясищев, А. Г. Ковалев, Л. И. Божович, В. А. Крутецкий, Н. Н. Обозов, Н. Д. Левитов и др.

Суть и содержание организаторских способностей наиболее полно раскрыты Л. И. Уманским, который выделял следующие базовые организаторские способности: «психологическая избирательность, практический психологический ум, психологический такт, общественная энергичность, требовательность, критичность, склонность к организаторской деятельности» (там же: 44; см. также: Сарычев, Логвинов, 2019: 159-161).

\section{ПРОГРАММА ЭМПИРИЧЕСКОГО ИССЛЕДОВАНИЯ}

Цель исследования - определить взаимосвязь между отдельными компонентами эмоционального интеллекта с коммуникативными и организаторскими способностями.

\section{Эмпирические задачи исследования:}

1) подобрать методический инструментарий изучения взаимосвязи между эмоциональным интеллектом и коммуникативными способностями, провести эмпирическое исследование;

2) собрать, обработать и проанализировать результаты исследования по данной теме;

3) выявить взаимосвязи компонентов эмоционального интеллекта с коммуникативными и организаторскими способностями;

4) рассмотреть взаимосвязи компонентов эмоционального интеллекта с коммуникативными и организаторскими способностями.

Выборку нашего исследования составляют 40 мужчин и женщин, являющихся студентами высших учебных заведений, очного и очно-заочного отделений.

Объектом исследования являются мужчины и женщины в возрасте 18 37 лет.

Предметом исследования являются эмоциональный интеллект и коммуникативные способности у мужчин и женщин.

\section{Гипотезы исследования:}

1) существует взаимосвязь между шкалой эмоционального интеллекта «Эмпатия» (по Н. Холлу) и коммуникативными способностями; 
2) существует взаимосвязь между шкалой «Понимание чужих эмоций» (МП, по Д. В. Люсину) и коммуникативными способностями;

3) существует взаимосвязь между шкалой «внутриличностный эмоциональный интеллект» (ВЭИ, по Д. В. Люсину) и организаторскими способностями;

4) существует взаимосвязь между шкалой «Управление эмоциями» (УЭ, по Д. В. Люсину) и организаторскими способностями.

База исследования. В исследовании приняли участие обучающиеся различных факультетов АНО ВО «Московский гуманитарный университет» и университета «Синергия» общей численностью 40 человек, из которых мужчин - 12 человек, женщин - 28 человек.

В процессе исследования мы пользовались следующими методиками:

1) опросник «Диагностика “эмоционального интеллекта”» Н. Холла;

2) опросник «ЭмИн» Д. В. Люсина;

3) опросник «Коммуникативные и организаторские склонности» В. В. Синявского и В. А. Федорошина (КОС).

\section{РЕЗУЛЬТАТЫ ЭМПИРИЧЕСКОГО ИССЛЕДОВАНИЯ}

Результаты психодиагностики респондентов по вышеуказанным методикам позволили нам получить следующие результаты:

- большинство испытуемых продемонстрировали выраженные показатели по шкалам эмоционального интеллекта, так или иначе связанных с эмоциями других людей или межличностным эмоциональным интеллектом (шкала «Эмоциональная осведомленность - 27 \%, шкала «Эмпатия» 25 \%, шкала «Распознавание эмоций других людей» - 27 \%, шкала «Понимание чужих эмоций» — 29 \%, шкала «Управление чужими эмоциями» $24 \%)$

- лишь небольшой процент всех респондентов приходится на шкалы эмоционального интеллекта, связанные с пониманием своих эмоций и внутриличностным интеллектом;

- практически равное количество респондентов от всей выборки обладает и коммуникативными, и организаторскими способностями (шкала «Коммуникативные склонности» — 47 \% шкала «Организаторские склонности» $-53 \%)$.

- $\quad$ в среднем, по различным шкалам эмоционального интеллекта, выделенным Н. Холлом и Д. В. Люсиным, преобладают низкие и средние значения, в частности, шкала «Интегративный уровень эмоционального интеллекта» (Н. Холл) представлена в равной степени низким $(47,5$ \%) и средним 
значениями (47,5 \%), а шкала «Общий эмоциональный интеллект» (Д. В. Люсин) характеризуется преимущественно средним значением (47,5\%).

Проанализировав первичные распределения испытуемых по низкому, среднему и высокому уровню выраженности компонентов эмоционального интеллекта, мы обнаружили преобладание низких и средних значений. Так, согласно методике Н. Холла, которая включает в себя низкую, среднюю и высокую степень выраженности, шкала «Интегративный эмоциональный интеллект» представлена в равной степени низким (47,5\%) и средним $(47,5 \%)$ уровнями, т. е. количество испытуемых с низким и средним уровнем эмоционального интеллекта по данной шкале в нашей выборке одинаково. Наглядно данные результаты приведены на рисунке 1.

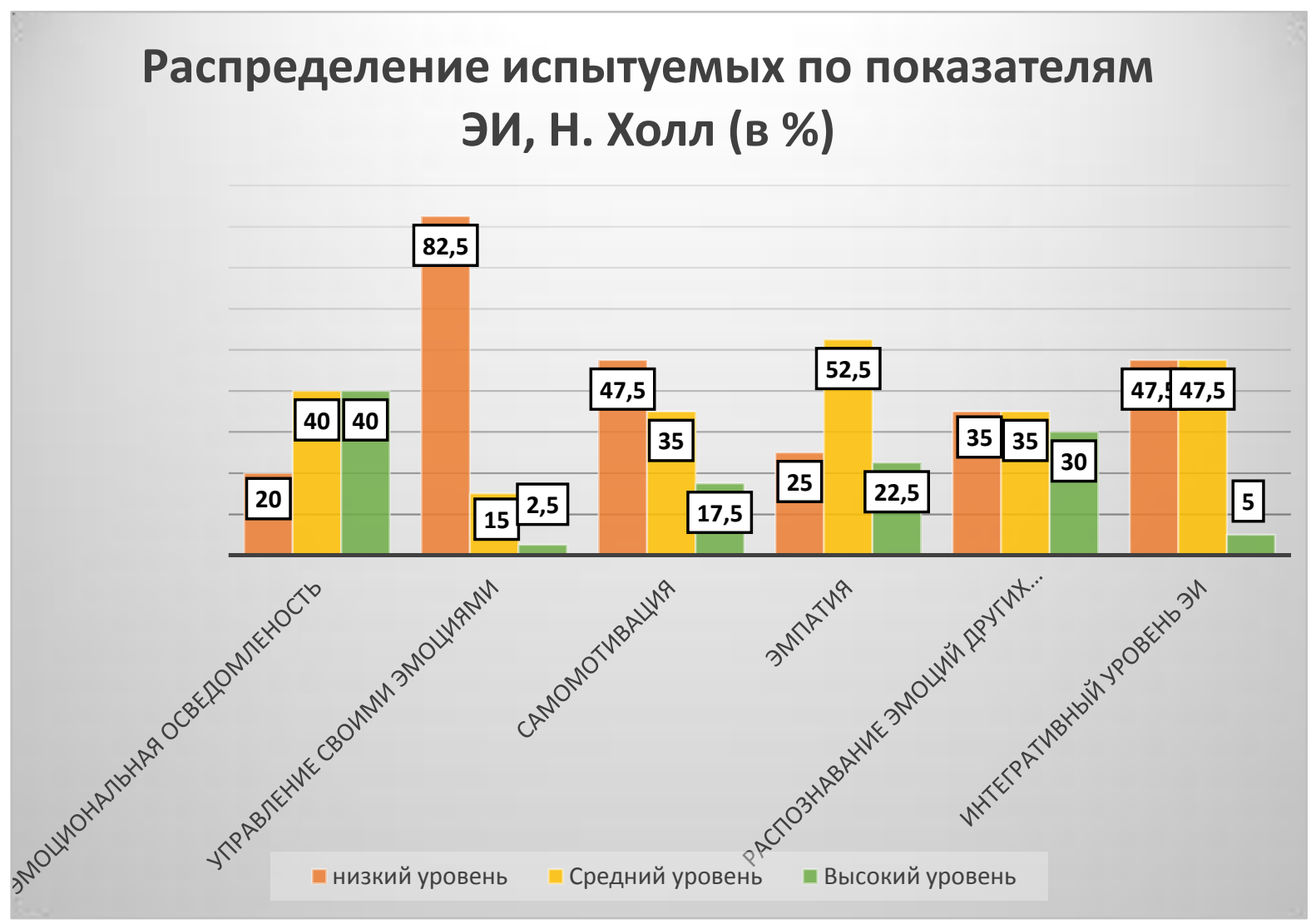

Puc. 1 .

Данные методики ЭмИн Д. В. Люсина, включающей в себя 5 уровней выраженности, а именно: очень низкий, низкий, средний, высокий и очень высокий, показывают преобладание средних значений в нашей выборке, вслед за которыми по величине идут низкое и очень низкое значения (шкала «Общий эмоциональный интеллект» - среднее значение 47,5\%, низкое значение $17,5 \%$, очень низкое значение $12,5 \%$ ). Наглядно эти данные представлены на рисунке 2. 


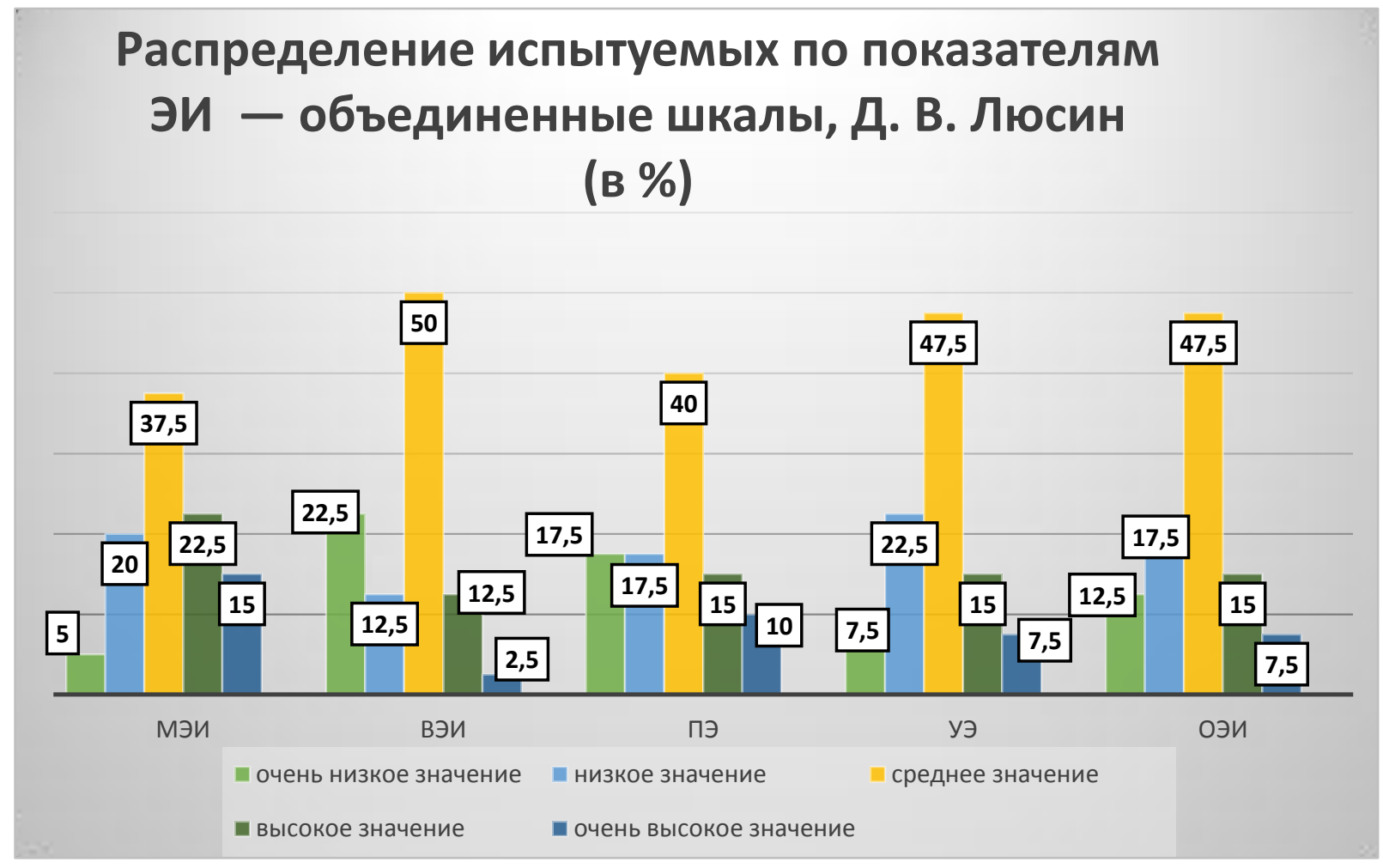

Puc. 2.

Распределение испытуемых по шкалам методики КОС В. В. Синявского и В. А. Федорошина показало, что от всей совокупности испытуемых по коммуникативным способностям превалируют средние показатели (25\%), показатели ниже среднего (20\%) и низкие (30 \%). Выражены также очень высокие значения $(22,5 \%)$. Организаторские же способности представлены в основном низкими (низкий уровень - $30 \%$, уровень ниже среднего $22,5 \%$ ) или высокими (высокий уровень - $25 \%$, очень высокий уровень $15 \%$ ), в то время как средние показатели по этой шкале выражены очень слабо, всего 7,5 \%. Описываемые результаты представлены на рисунке 3.

С целью проверки выдвинутых нами гипотез был проведен корреляционный анализ при помощи компьютерной программы STATISTICA 8.0. Peзультаты анализа показали, что существуют множество корреляционных связей между шкалами эмоционального интеллекта и коммуникативными и организаторскими способностями. Однако нас больше всего интересовали наличие и характер взаимосвязей между переменными, заявленными в наших гипотезах.

Нами была выявлена умеренная корреляционная взаимосвязь $(r=0,38)$ между шкалами «Эмпатия» и «Коммуникативные способности». Также обнаружена умеренная корреляционная взаимосвязь $(r=0,37)$ между шкалами «Понимание чужих эмоций» и «Коммуникативные способности», что подтверждает гипотезы 1 и 2. Между шкалами «Внутриличностный эмоциональ- 
ный интеллект» и «Организаторские способности», «Управление эмоциями» и «Организаторские способности» не было выявлено статистически значимых взаимосвязей. Следовательно, гипотезы 3 и 4 не нашли подтверждения.

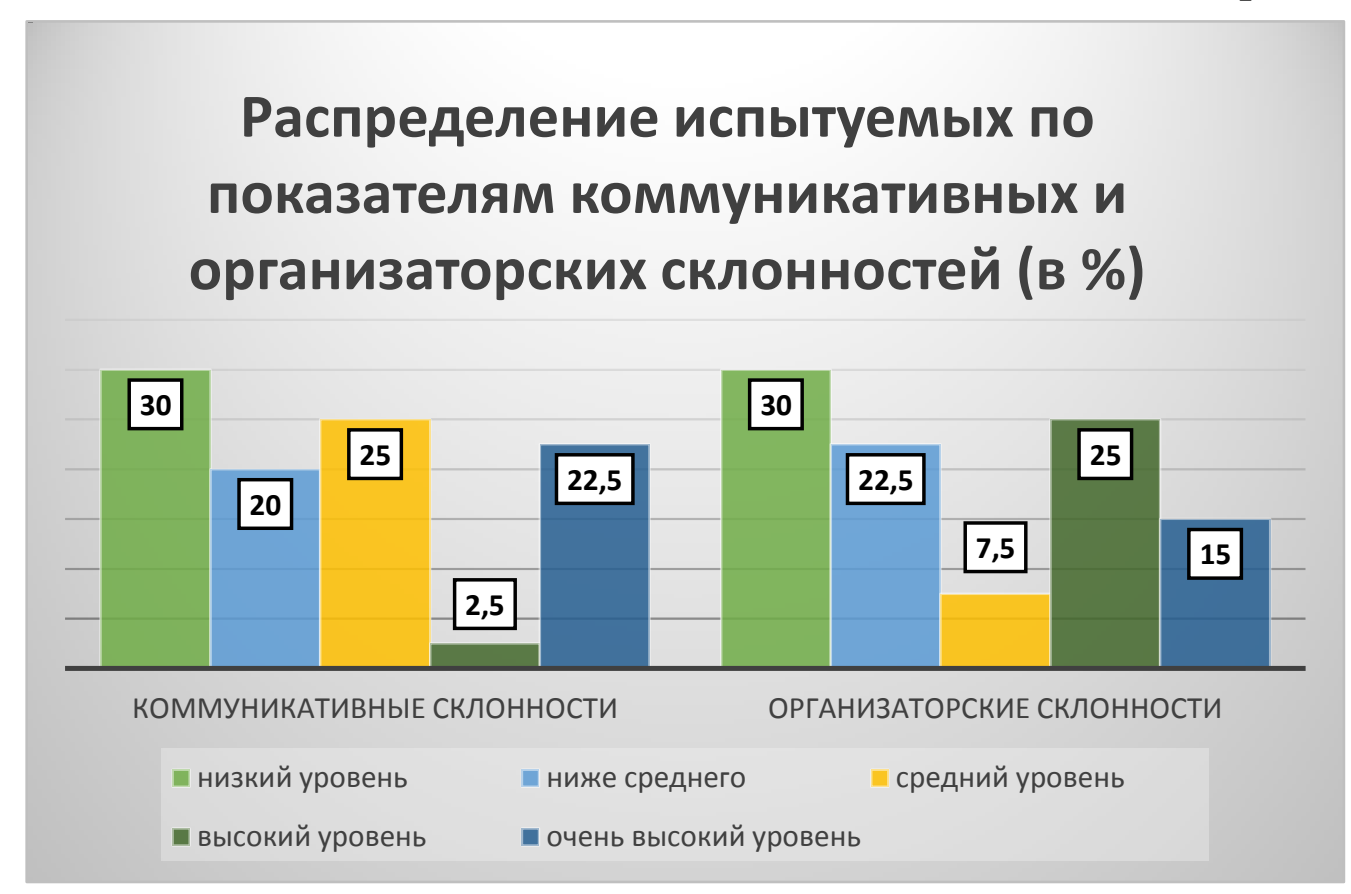

Puc. 3.

\section{ЗАКЛЮЧЕНИЕ}

Подводя итоги, можно сказать, что эмоциональный интеллект представляет собой многогранное явление, включающее в себя большое количество компонентов, связанных как с собственными эмоциями человека (способность понимать их, управлять ими и т. д.), так и с эмоциями окружающих его людей (способность распознавать чужие эмоции, эмпатия и т. д.). Сущность феномена эмоционального интеллекта интерпретируются с позиций многих современных теорий и подходов.

Коммуникативные способности личности относятся к специальным способностям и были изучены многими исследователями именно с точки зрения места, занимаемого данным видом способностей в иерархии человеческих способностей. Роль навыков коммуникации особенно возросла в современном обществе, в связи с чем увеличивается интерес к практико-ориентированным исследованиям данного феномена.

Также немалое значение отводится и организаторским способностям, включающим в себя несколько личностных характеристик (Сарычев, Логвинов, 2019: 159-161). Коммуникативные и организаторские способности личности являлись предметом изучения многих отечественных ученых.

По результатам нашего эмпирического исследования эмоциональный интеллект у опрошенных студентов в основном представлен средними и низ- 
кими показателями по шкалам, выделенным Н. Холлом и Д. В. Люсиным. Следует отметить, что наиболее низкие показатели выявлены по шкалам, связанным с внутриличностным эмоциональным интеллектом, т. е. пониманием и управлением собственными эмоциями. Так, результаты по шкале «Управление своими эмоциями» (Н. Холл) составляют всего $2 \%$.

Также нами было выявлено, что коммуникативные и организаторские способности у опрошенных студентов выражены в практически одинаковой степени, при этом существуют различия в распределении испытуемых по показателям обеих склонностей.

По итогам исследования мы можем констатировать, что наша общая гипотеза о существовании взаимосвязи между шкалами эмоционального интеллекта, с одной стороны, и коммуникативными и организаторскими способностями - с другой, нашла подтверждение. В частности, были подтверждены гипотезы 1 и 2. Следовательно, можно сделать вывод о том, что внимание к эмоциям других людей, способность понимать их чувства и сопереживать могут способствовать более эффективной коммуникации, что подтверждает значение и важность эмоциональной сферы в жизни человека.

Результаты нашего эмпирического исследования могут быть полезны и интересны педагогам, преподавателям, работающим с людьми позднего юношеского (18-21), молодого (20-30) и зрелого (30-37) возраста, а также всем желающим ознакомиться с данной темой.

В дальнейшем исследование по изученной нами теме можно расширить благодаря включению в состав выборки большего количества лиц обоих полов и, возможно, более зрелого возраста в целях сравнения выраженности эмоционального интеллекта, коммуникативных и организаторских способностей у молодых и более зрелых людей. Также нам представляется интересным использование метода факторного анализа с целью выявления скрытых факторов, влияющих на характер взаимосвязей шкал эмоционального интеллекта с коммуникативными и организаторскими способностями.

\section{СПИСОК ЛИТЕРАТУРЫ}

Аникеева, Ю. В. (2012) Психологические детерминанты развития коммуникативных способностей студентов-психологов : автореф. дис. ... канд. псих. наук. Сочи. 28 с. URL: https://dlib.rsl.ru/viewer/01005053217 (дата обращения: 12.04.2019).

Бабудоржиева, Э. Д. (2012) Исследование проблемы коммуникативных и организаторских способностей в психологии // Вестник БГУ. Образование. Личность. Общество. № 5. С. 41-45. 
Большой психологический словарь (2009) / под ред. Б. Г. Мещерякова, В. П. Зинченко. 4-е изд., расш. М. : АСТ ; АСТ Москва ; СПб. : ПраймЕврознак. 811, [5] с.

Гоулман, Д. (2018) Эмоциональный интеллект. Почему он может значить больше, чем IQ / пер. с англ. А. П. Исаевой. 6-е изд. М. : Манн, Иванов и Фербер. 535, [2] c.

Гоулман, Д., Бояцис, Р., Макки, А. (2018) Эмоциональное лидерство: искусство управления людьми на основе эмоционального интеллекта / пер. с англ. 11-е изд. М. : Альпина Паблишер. 301 с.

Ильин, Е. П. (2001) Эмоции и чувства. СПб. : Питер. 752 с.

Карузо, Д., Сэловей, П. (2018) Эмоциональный интеллект руководителя: как развивать и применять. СПб. : Питер. 320 с. (Серия «Деловой бестселлер»).

Люсин, Д. В. (2004) Современные представления об эмоциональном интеллекте // Социальный интеллект: теория, измерение, исследования / под ред. Д. В. Люсина, Д. В. Ушакова. М. : Институт психологии РАН. 176 с. С. 29-36.

Люсин, Д. В. (2006) Новая методика для измерения эмоционального интеллекта: опросник ЭмИн // Психологическая диагностика. № 4. С. 3-22.

Сарычев, С. В., Логвинов, И. Н. (2019) История психологии : учеб. пос. для академ. бакалавриата : в 2 ч. 2-е изд., испр. и доп. М. : Юрайт. Ч. 2. 211 с. (Серия «Университеты России»).

Bar-On, R. (1997) The emotional intelligence inventory (EQ-i): Technical manual. Toronto : Multi-Health Systems. x, 85 p.

Bar-On, R. (2000) Emotional and social intelligence: Insights from the emotional quotient inventory // Handbook of emotional intelligence: Theory, development, assessment, and application at home, school, and in the workplace / ed. by R. Bar-On, J. D. A. Parker. San Francisco : Jossey-Bass. xv, 528 p. P. 363-388.

Buck, R. (1991) Motivation, emotion, and cognition: A developmentalinteractionist view // International review of studies on emotion. Vol. $1 /$ ed. by K. T. Strongman. Chichester : J. Wiley \& Sons. xi, 363 p. P. 101-142.

Cattell, R. B. (1971) Abilities: Their structure, growth, and action. Boston : Houghton Mifflin. xxii, 583 p.

Gardner, H. (1993) Frames of mind: The theory of multiple intelligences. (10th anniversary edn.) N. Y. : Basic Books. lii, 467 p.

Goleman, D. (1995) Emotional intelligence. N. Y. : Bantam Books. xiv, 352 p. 
Goleman, D., Boyatzis, R., McKee, A. (2002) Primal leadership: Learning to lead with emotional intelligence. Boston, MA : Harvard Business School Press. xvii, $306 \mathrm{p}$.

Guilford, J. P. (1967) The nature of human intelligence. N. Y. : McGrawHill. 538 p.

Kets de Vries, M. F. R. (2001) The leadership mystique: A user's manual for the human enterprise. L. : Financial Times Prentice Hall. xxvi, 326 p.

Mayer, J. D., Caruso, D. R., Salovey, P. (1999) Emotional intelligence meets traditional standards for an intelligence // Intelligence. Vol. 27. Issue 4. P. 267298. DOI: $10.1016 / \mathrm{S} 0160-2896(99) 00016-1$

Salovey, P., Mayer, J. D. (1990) Emotional intelligence // Imagination, Cognition and Personality. Vol. 9. Issue 3. P. 185-211. DOI: 10.2190/DUGG-P24E$\underline{52 \mathrm{WK}-6 \mathrm{CDG}}$

Spearman, Ch. E. (1927) The abilities of man: Their nature and measurement. N. Y. : Macmillan. vi, 415, xxxiii p.

Thurstone, L. L. (1947) Multiple-factor analysis: A development and expansion of "The Vectors of the Mind". Chicago : University of Chicago Press. xix, 535 p.

Wechsler, D. (1955) Manual for the Wechsler adult intelligence scale. N. Y. : Psychological Corporation. vi, $110 \mathrm{p}$.

Дата поступления: 15.06.2019 2.

\section{REFERENCES}

Anikeeva, Yu. V. (2012) Psikhologicheskie determinanty razvitiia kommunikativnykh sposobnostei studentov-psikhologov [Psychological determinants of communicative abilities development in psychology majors] : Abstract of the diss. ... Candidate of Psychology. Sochi. 28 p. [online] Available at: https://dlib.rsl.ru/viewer/01005053217 (accessed 12.04.2019). (In Russ.).

Babudorzhieva, E. D. (2012) Issledovanie problemy kommunikativnykh i organizatorskikh sposobnostei $\mathrm{v}$ psikhologii [A study of the problem of communicative and organizational abilities in psychology]. Vestnik BGU. Obrazovanie. Lichnost'. Obshchestvo, no. 5, pp. 41-45. (In Russ.).

Bol'shoi psikhologicheskii slovar' [Unabridged psychological dictionary] (2009) / ed. by B. G. Meshcheriakov and V. P. Zinchenko. 4th edn., enlarged. Moscow : AST Publ. ; AST Moskva Publ. ; St. Petersburg : Praim-Evroznak Publ. 811, [5] p. (In Russ.).

Goleman, D. (2018) Emotsional'nyi intellekt. Pochemu on mozhet znachit' bol'she, chem IQ [Emotional intelligence: Why it can matter more than IQ] I 
transl. from English by A. P. Isaeva. 6th edn. Moscow : Mann, Ivanov \& Ferber Publ. 535, [2] p. (In Russ.).

Goleman, D., Boyatzis, R. E. and McKee, A. (2018) Emotsional'noe liderstvo: iskusstvo upravleniia liud'mi na osnove emotsional'nogo intellekta [Primal leadership: Learning to lead with emotional intelligence] / transl. from English. 11th edn. Moscow : Alpina Publisher. 301 p. (In Russ.).

Ilyin, E. P. (2001) Emotsii i chuvstva [Emotions and feelings]. St. Petersburg : Piter Publ. 752 p. (In Russ.).

Caruso, D. R. and Salovey, P. (2018) Emotsional'nyi intellekt rukovoditelia: kak razvivat' i primeniat' [The emotionally intelligent manager: How to develop and use the four key emotional skills of leadership]. St. Petersburg : Piter Publ. 320 p. (Series "Delovoi bestseller" / "Business bestseller"). (In Russ.).

Liusin, D. V. (2004) Sovremennye predstavleniia ob emotsional'nom intellekte [Modern concepts of emotional intelligence]. In: Sotsial'nyi intellekt: teoriia, izmerenie, issledovaniia [Social intelligence: Theory, measurement, research] / ed. by D. V. Liusin and D. V. Ushakov. Moscow : Institute of Psychology, RAS. 176 p. Pp. 29-36. (In Russ.).

Liusin, D. V. (2006) Novaia metodika dlia izmereniia emotsional'nogo intellekta: oprosnik EmIn [A new method for measuring emotional intelligence: EmIn questionnaire]. Psikhologicheskaia diagnostika, no. 4. pp. 3-22. (In Russ.).

Sarychev, S. V. and Logvinov, I. N. (2019) Istoriia psikhologii [History of psychology] : A study guide : in 2 parts. 2nd edn., revised and enlarged. Moscow : Iurait Publ. Ch. 2. 211 p. (Series "Universitety Rossii" / "Universities of Russia"). (In Russ.).

Bar-On, R. (1997) The emotional intelligence inventory (EQ-i): Technical manual. Toronto : Multi-Health Systems. x, 85 p.

Bar-On, R. (2000) Emotional and social intelligence: Insights from the emotional quotient inventory. In: Handbook of emotional intelligence: Theory, development, assessment, and application at home, school, and in the workplace / ed. by R. Bar-On and J. D. A. Parker. San Francisco : Jossey-Bass. xv, 528 p. Pp. 363388.

Buck, R. (1991) Motivation, emotion, and cognition: A developmentalinteractionist view. In: International review of studies on emotion, vol. 1 / ed. by K. T. Strongman. Chichester : J. Wiley \& Sons. xi, 363 p. Pp. 101-142.

Cattell, R. B. (1971) Abilities: Their structure, growth, and action. Boston : Houghton Mifflin. xxii, 583 p.

Gardner, H. (1993) Frames of mind: The theory of multiple intelligences. (10th anniversary edn.) New York : Basic Books. lii, 467 p. 
Goleman, D. (1995) Emotional intelligence. New York : Bantam Books. xiv, $352 \mathrm{p}$.

Goleman, D., Boyatzis, R. and McKee, A. (2002) Primal leadership: Learning to lead with emotional intelligence. Boston, MA : Harvard Business School Press. xvii, 306 p.

Guilford, J. P. (1967) The nature of human intelligence. New York : McGraw-Hill. 538 p.

Kets de Vries, M. F. R. (2001) The leadership mystique: A user's manual for the human enterprise. London : Financial Times Prentice Hall. xxvi, 326 p.

Mayer, J. D., Caruso, D. R. and Salovey, P. (1999) Emotional intelligence meets traditional standards for an intelligence. Intelligence, vol. 27, issue 4, pp. 267-298. DOI: 10.1016/S0160-2896(99)00016-1

Salovey, P. and Mayer, J. D. (1990) Emotional intelligence. Imagination, Cognition and Personality, vol. 9, issue 3, pp. 185-211. DOI: 10.2190/DUGGP24E-52WK-6CDG

Spearman, Ch. E. (1927) The abilities of man: Their nature and measurement. New York : Macmillan. vi, 415, xxxiii p.

Thurstone, L. L. (1947) Multiple-factor analysis: A development and expansion of "The Vectors of the Mind". Chicago : University of Chicago Press. xix, 535 p.

Wechsler, D. (1955) Manual for the Wechsler adult intelligence scale. New York : Psychological Corporation. vi, $110 \mathrm{p}$.

Submission date: 15.06.2019.

Полянский Андрей Иванович - доцент кафедры общей психологии и истории психологии Московского гуманитарного университета. Адрес: 111395, Россия, г. Москва, ул. Юности, 5, корп. 3, каб. 419. Тел.: +7 (499) 374-67-20. Эл. адрес: aipol-69@ mail.ru

Polyansky Andrey Ivanovich, Associate Professor, Department of General Psychology and History of Psychology, Moscow University for the Humanities. Postal address: R. 419, Bldg. 3, 5 Yunosti St., 111395 Moscow, Russian Federation. Tel.: +7 (499) 374-67-20. E-mail: aipol-69@ mail.ru

SPIN-код РИНЦ: 2226-4192 
Быковская Любовь Игоревна - бакалавр пятого года обучения, факультет психологии, педагогики и социологии Московского гуманитарного университета. Адрес: 111395, Россия, г. Москва, ул. Юности, 5, корп. 3. Эл. адрес: bikovskayali@mail.ru

Bykovskaya Lubov Igorevna, 5th year bachelor, Faculty of Psychology, Pedagogy and Sociology, Moscow University for the Humanities. Postal address: Bldg. 3, 5 Yunosti St., 111395 Moscow, Russian Federation. E-mail: bikovskayali @mail.ru

SPIN-код РИНЦ: $\underline{\text { 3478-1894 }}$

Для циитирования:

Полянский А. И., Быковская Л. И. Эмоциональный интеллект и коммуникативные способности современных студентов [Электронный ресурс] // Горизонты гуманитарного знания. 2019. № 4. C. 81-95. URL: http://journals. mosgu.ru/ggz/article/view/1062 (дата обращения: дд.мм.гггг). DOI: 10.17805/ ggz.2019.4.6 